\title{
Utilization of 4-n-nonylphenol by Metarhizium sp. isolates*
}

\author{
Sylwia Różalska', Julia Pawłowska², Marta Wrzosek², Cezary Tkaczuk³ and Jerzy Długoński1凶 \\ 1Department of Industrial Microbiology and Biotechnology, Faculty of Biology and Environmental Protection, University of Łódź, Łódź, Poland \\ 2Department of Systematics and Plant Geography, Faculty of Biology, University of Warsaw, Warsaw, Poland; ${ }^{3}$ Department of Plant Protection, \\ Faculty of Natural Sciences, Siedlce University of Natural Sciences and Humanities, Siedlce, Poland
}

\begin{abstract}
Nonylphenol (4-NP) is a xenobiotic classified as an endocrine disrupting compound with an ability to interfere with hormonal systems of numerous organisms including humans. It is widely distributed not only in aquatic but also in terrestrial systems. The aim of this study was to evaluate the ability of cosmopolitan fungus Metarhizium (commonly persistent in soil as a facultative insect pathogen, controlling populations of arthropods in natural environment) to degrade 4-n-nonylphenol. All isolates examined in this work were identified to a species rank based on five, independent genetic markers. Among eight Metarhizium strains; six of them have been identified as $M$. robertsii, and two others as $M$. brunneum and M. lepidiotae. All investigated Metarhzium isolates were found to eliminate 4-n-NP with significant efficiency (initial xenobiotic concentration $50 \mathrm{mg} \mathrm{L}^{-1}$ ). The degradation process was very effective and at $24 \mathrm{~h}$ of incubation $50-90 \%$ of $4-n$-NP was eliminated by certain strains, while extended incubation resulted in further utilization of this compound. At the end of the experiments 64$99 \%$ of $4-n$-NP was removed from the culture medium. Additionally, in all tested cultures three major metabolites were detected: 4-hydroxybenzoic acid; 2-(4-hydroxyphenyl)acetic acid and 4-hydroxyphenylpentanoic acid. The obtained results indicate that Metarhizium sp. possesses an ability to degrade NP and can serve as a potential candidate for further biodegradation studies.
\end{abstract}

Key words: Metarhizium, nonylphenol biodegradation, molecular identification, virulence

Received: 30 October, 2013; revised: 02 December, 2013; accepted: 03 December, 2013; available on-line: 30 December, 2013

\section{INTRODUCTION}

Endocrine disrupting compounds (EDCs) are defined as exogenous agents interfering with the production, metabolism or binding action of natural hormones in numerous organisms. Typical EDCs of anthropogenic origin with estrogen-like action include 4-nonylphenols (NPs), degradation products of nonionic surfactants nonylphenol polyetoxylates (Cajthaml et al., 2009). NPs are widely distributed in aquatic and terrestrial systems, causing deleterious effects in a variety of wildlife species. Moreover, they can bind to human estrogen receptors and stimulate hormone-dependent cancers (Brown et al., 2009). In recent years, there has been an increasing interest in the possibilities of introducing NP to soil ecosystems due to land application of biosolids (Brown et al., 2009; Langdon et al., 2011; Langdon et al., 2012; Kinney et al., 2012; Venkatesan \& Halden, 2013). In soil, NP decreases earthworm and collembolan reproduction and leads to plant growth reduction (Domene et al., 2009). Moreover, these toxic compounds introduced to soil have a deleterious effect on soil microbial activity (Ojeda et al., 2013).

The genus of Metarbizium Sorokin includes several valuable entomopathogenic fungi, which are used in biological control (Roberts \& Leger 2004). They are widely dispersed in nature and commonly isolated from infected insect carcases or soil in almost every climatic zone (Lomer et al., 2001; Amóra et al., 2010). Metarbizium strains are also successfully used as an alternative to chemical insecticides in many biocontrol programmes, and are an effective pathogen for locusts, grasshoppers (Acrididae) and ticks (Acari) (Lomer et al., 2001; Fernandes et al., 2012). Although, Metarbizium sp. are facultative insect pathogens controlling populations of arthropods in natural environment, their natural habitat is soil, not insects (Bidochka et al., 2001; Wyrebek et al., 2011). The abundance of Metarbizium in soil has been described many times and it has been estimated that the number of Metarbizium propagules can reach even 1 x $10{ }^{6}$ per $\mathrm{g}$ of the soil (Milner, 1992). Metarbizium sp. are not randomly distributed in soils, but show plant-rhizospherespecific associations and they are of great importance to the environment.

Microorganisms have permanent contact with various wide-spread, hazardous contaminants, including pesticides, surfactants or toxic by-products of their transformation. The effects of xenobiotics on the soil microflora are of importance because many microbial functions are critical to soil sustainability or its environmental quality. Filamentous fungi grown in a polluted environment can transform or degrade hazardous compounds, which may be an adaptive survival strategy under severe conditions (Jeon \& Madsen, 2012). This trend for biodegradation of certain toxic pollutants by filamentous fungi (Lisowska et al., 2006; Słaba et al., 2009; Różalska et al., 2010; Bernat \& Długoński, 2012) was also observed in our previous studies. As it was mentioned above, NP causes serious threats to soil ecosystems and Metarbizium sp. is an abun-

e-mail: jdlugo@biol.uni.lodz.pl

*Presented at the 3-rd Workshop on Microbiology "MIKROBIOT 2013" in Łódź, Poland.

Abbreviations: NP, 4-nonylphenol; 4-n-NP, 4-n-nonyphenol

Accession numbers of sequences presented in the paper: JX438643，JX438644，JX438645，JX438646，JX438647，JX438648， JX438650，JX438651，JX438652，JX438653，JX438654，JX438655， JX438657, JX438658, JX438659, JX438660, KC905137, KC905138, KC905139, KC905140, KC905141, KC905142, KC905143, KC905144, KC905145, KC905146, KC905147, KC905148, KC905149, KC905150, KC905151, KC905152, KC905154,KC905155, KF423433, KF423435, KF423437 
dant soil microorganism. Therefore, this species can take part in NP utilization.

In this work, we investigated whether Metarbizium isolates could degrade 4-n-nonyphenol (4-n-NP), an isomer with a non-branched, linear chain, typically used for biodegradation or detoxification studies. The removal of NP during the growth of the tested fungus with formation of degradation metabolites is presented. Moreover, several new Metarbizium isolates are described. Its identification to a species rank based on five genetic markers and their pathogenicity against insects is also confirmed.

\section{MATERIALS AND METHODS}

Fungal strains and cultivation techniques. The strains used in this study were fungal collections from the Department of Plant Protection, the University of Natural Sciences and Humanities in Siedlce, the Department of Industrial Microbiology and Biotechnology, the University of Lódź and the Herbarium of the University of Warsaw. A detailed description for the isolates is shown in Table 1 . The strains were maintained in accordance with standard microbiological protocols.

Morphological analysis. For the analysis, spores from 14-d-old cultures were washed from the slants with $0.85 \% \mathrm{NaCl}$. The generated suspensions were filtered, and the spores were stained with a Lactophenol Blue solution (Fluka). For a morphological assessment, at least 200 spores were photographed. For phialides measurements, a fragment of the fungal mycelium incubated on plates was collected and suspended in a Lactophenol Blue solution (Fluka). The images were acquired using an AxioCam HRc camera with an Axiovert 200 M (Zeiss, Germany) inverted fluorescence microscope equipped with a PlanApochromat objective (63x/1.4 oil). The images were acquired and automatic morphological measurements were performed using the AxioVision software (Zeiss, Germany).
DNA extraction, PCR amplification and sequencing. Genomic DNA was extracted from the fresh mycelium of 8 strains (Table 1) grown on PDA (Fluka Analytical, Germany) medium using the GeneMATRIX Plant \& Fungi DNA Purification Kit (EURx Ltd., Poland) following the manufacturer's instructions. The full ITS region was amplified using the primer pair ITS1f and ITS4 (White et al., 1990) and the TEF gene with the primers EF1-728f and EF1-986r (Carbone \& Kohn, 1999). The following primers were used to amplify intergenic regions described by Kepler and Rehner (2013): MzIGS3_1F, MzIGS3_4R, MzIGS2_2F, MzIGS2_3R, MzFG543igs_1F and MzFG543igs_4R. DNA was amplified and sequenced as described by Budziszewska et al. (2011). The temperature profiles were programmed as described by Luque et al. (2005) and Kepler and Rehner (2013). Sequence data generated for this study are available from the GenBank under the accession numbers presented in Table 2.

Phylogenetic analysis. ITS, TEF, MzIGS2, MzIGS3 and MzFG546igs sequences generated in this study (8 strains, Table 2) were assembled with 16 additional sequences retrieved from the GenBank and aligned in the SeaView version 4.3.5 program (Gouy et al., 2010) using the muscle method (Edgar, 2004). The final alignment was manually corrected. This dataset contained 3035 characters (including gaps). A maximum likelihood (ML) analysis was performed using PhyML v3.0 (Guindon et al., 2010) as implemented in SeaView (Gouy et al., 2010). For ML analysis, GTR model of substitution was used, the nucleotide frequencies were assumed empirical, invariable sites were ignored, the across site rate variation was optimized, the tree searching operation used was the best of NNI (nearest-neighbor interchange) and SPR (subtree pruning and regrafting). Tree robustness was evaluated using a 100-replicate bootstrap analysis. The phylograms were visualized in TreeView version 1.6.6. M. acridum (ARSEF 7486) and Metarbizium globosum (ARSEF 2596) were used as an outgroup.

Table 1. Description of the strains used herein

\begin{tabular}{|c|c|c|c|c|c|}
\hline Strain no./ collection & Current name & Colony color code & Conidia (mm) & Phialides (mm) & Isolation source \\
\hline WA27855/UPH Siedlce & Metarhizium robertsii & $\begin{array}{l}\text { Hay's green }(33 \mathrm{k}), \\
\text { Dark Yellowish Green } \\
(33 \mathrm{~m}), \text { Dark Green } \\
(35 \mathrm{~m})\end{array}$ & $3-4 \times 6-7$ & $\begin{array}{l}2-3 \times \\
13-14.5\end{array}$ & $\begin{array}{l}\text { Meadow soil, Chodów } \\
\text { 1, Poland }\end{array}$ \\
\hline WA27856/UPH Siedlce & Metarhizium robertsii & $\begin{array}{l}\text { Hay's green (33k), } \\
\text { Dark Yellowish Green } \\
(33 \mathrm{~m}), \text { Dark Green } \\
(35 \mathrm{~m})\end{array}$ & $\begin{array}{l}2.5-3.5 \times \\
6-7\end{array}$ & $\begin{array}{l}2-3 \times \\
10-18.5\end{array}$ & $\begin{array}{l}\text { Meadow soil, Chodów } \\
2 \text {, Poland }\end{array}$ \\
\hline WA27938/UPH Siedlce & Metarhizium robertsii & $\begin{array}{l}\text { Hay's green (33k), } \\
\text { Dark Yellowish Green } \\
(33 \mathrm{~m}), \text { Dark Green } \\
(35 \mathrm{~m})\end{array}$ & $3-4 \times 6-7.5$ & $\begin{array}{l}2-3 \times \\
10-18.5\end{array}$ & $\begin{array}{l}\text { Imago Hylobius abietis, } \\
\text { Krynka, Poland }\end{array}$ \\
\hline WA27939/UPH Siedlce & Metarhizium robertsii & $\begin{array}{l}\text { Hay's green (33k), } \\
\text { Dark Yellowish Green } \\
(33 \mathrm{~m}), \text { Dark Green } \\
(35 \mathrm{~m})\end{array}$ & $3-4 \times 6-7.5$ & $\begin{array}{l}2-3 \times \\
10-12\end{array}$ & $\begin{array}{l}\text { Farmland, Zawady, } \\
\text { Poland }\end{array}$ \\
\hline WA27853/UPH Siedlce & $\begin{array}{l}\text { Metarhizium lepi- } \\
\text { diotae }\end{array}$ & $\begin{array}{l}\text { Plate LII: } 35 \text {,'"Storm } \\
\text { Grey }\end{array}$ & $\begin{array}{l}2.5-3.5 \times \\
6.5-8\end{array}$ & $\begin{array}{l}2.5-3 \times \\
17.5-22\end{array}$ & $\begin{array}{l}\text { Orchard soil, Polubicze, } \\
\text { Poland }\end{array}$ \\
\hline IM 2358/UŁ Łódź* & Metarhizium robertsii & $\begin{array}{l}\text { Plate XXXII: } 35^{\prime \prime} f \text { Pale } \\
\text { olivine, } 35^{\prime \prime} \mathrm{d} \text { Olivine }\end{array}$ & $\begin{array}{l}3.5-4 \times \\
6-7.5\end{array}$ & $\begin{array}{l}2-3 \times \\
10-15\end{array}$ & $\begin{array}{l}\text { Horticultural soil, Łódź, } \\
\text { Poland }\end{array}$ \\
\hline IM 6511/UŁ Łódź & Metarhizium robertsii & $\begin{array}{l}\text { Plate XVII 29d: Light } \\
\text { Lumiere Green }\end{array}$ & $3-4 \times 6.5-8$ & $2-3 \times 10-18.5$ & $\begin{array}{l}\text { Horticultural soil, Łódź, } \\
\text { Poland }\end{array}$ \\
\hline WA27848/UPH Siedlce & $\begin{array}{l}\text { Metarhizium brun- } \\
\text { neum }\end{array}$ & $\begin{array}{l}\text { Plate XVIII 31' m Var- } \\
\text { ley Green }\end{array}$ & $\begin{array}{l}2.5-3.5 \times \\
6.5-7.5\end{array}$ & $\begin{array}{l}2-3 \times \\
10-12.5\end{array}$ & $\begin{array}{l}\text { Tipulidae larva, Salmo- } \\
\text { pol, Poland }\end{array}$ \\
\hline
\end{tabular}

*previously identified as G. simplex IM 2358 


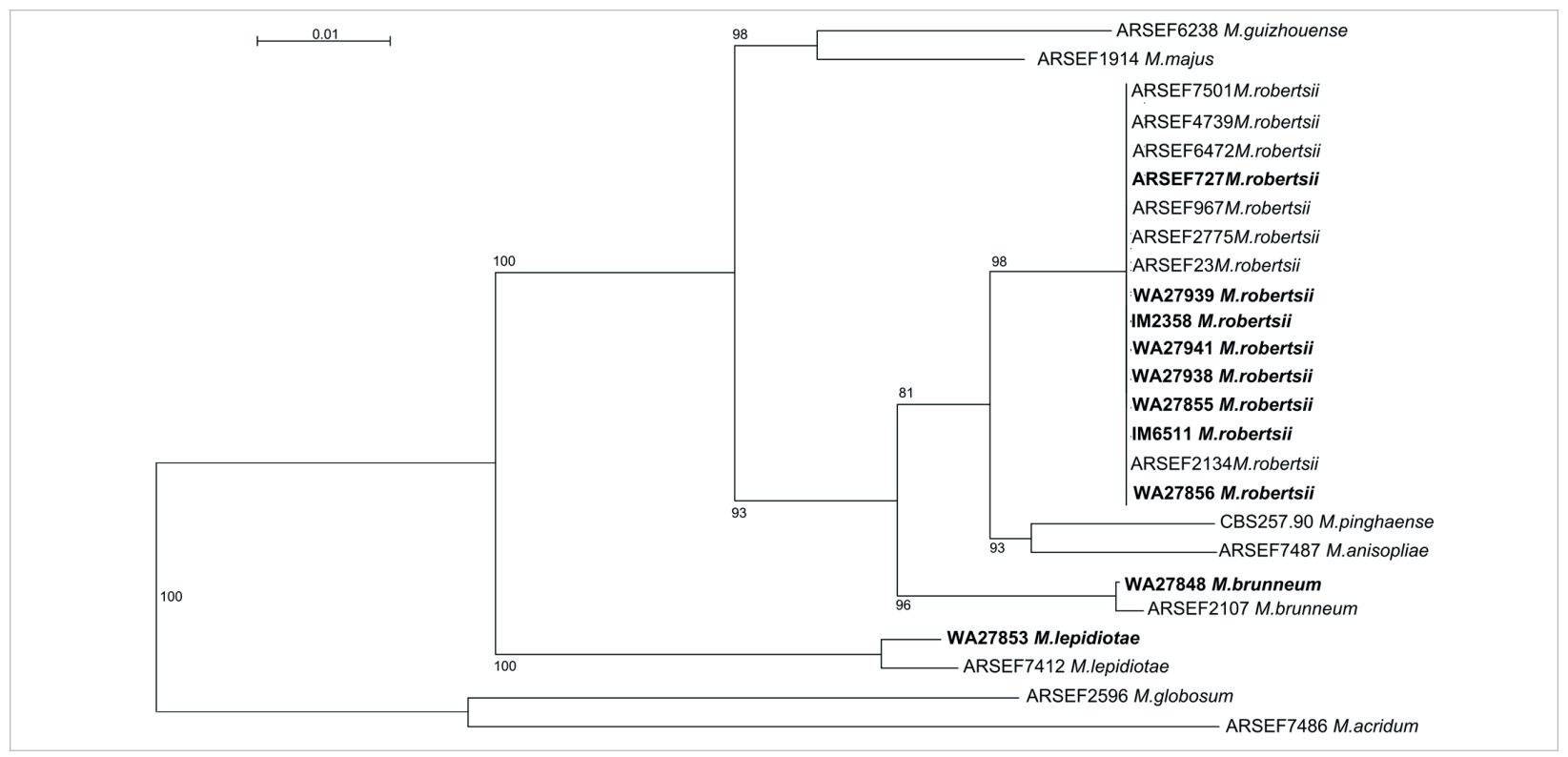

Figure 1. Maximum-likelihood (ML) tree for the Metarhizium anisopliae complex.

Strains isolated during this study are in bold blue. The bootstrap values are on tree nodes.

Virulence experiments. Galleria mellonella larvae for the 4th instar were collected from the laboratory culture on honeybee wax combs. Conidia were harvested from a 3-week-old culture surface under aseptic conditions by flooding the plate with sterile distilled water, scraping the colony with a surgical scalpel and stirring it into a suspension of $0.05 \%$ Tween 80 in $200 \mathrm{~mL}$ SDW for 20 min. After filtration, the conidial concentration in each suspension was calculated as $1.5 \times 10^{6} \mathrm{~mL}^{-1}$, which was determined using a Fuchs-Rosenthal haemocytometer. Larvae from the 4th instar were placed in conidial suspensions with the investigated fungal isolates. Submersion for $15 \mathrm{~s}$ was used for ten larvae per replicate. The treatment was repeated ten times for each isolate. Control larvae were dipped in a water solution with $0.1 \%$ Tween 80. After treatment, each group of ten larvae was placed in a sterilized moist chamber composed of a Petri dish lined with wet filter paper in the dark at $25^{\circ} \mathrm{C}$. Larval mortality was measured daily, and after each mortality measurement, dead larvae were removed from the dishes and transferred into sterile Petri dishes lined with wet filter paper.

Biodegradation experiments. For biodegradation experiments, spores from 14-d-old cultures on ZT slants were used to inoculate $20 \mathrm{~mL}$ of Sabouraud medium (Difco) in $100 \mathrm{~mL}$ Erlenmayer flasks, as described previously (Różalska et al., 2010). After 24h of incubation, the precultures were transferred to fresh minimal medium at a 1:9 ratio. The medium was also supplemented with 50 $\mathrm{mg} \mathrm{L} \mathrm{L}^{-1}$ of $4-n$-NP dissolved in ethanol (stock solution $20 \mathrm{mg} \mathrm{mL} \mathrm{mL}^{-1}$ ). Control abiotic (uninoculated) cultures were also prepared. The samples were incubated on a rotary shaker $(150 \mathrm{rpm})$ at $28^{\circ} \mathrm{C}$. At 24 and $48 \mathrm{~h}$, the culture samples were withdrawn for analysis.

4- $\boldsymbol{n}$-NP determination. Samples were extracted using a method described previously (Różalska et al., 2010). The extracts were analysed through gas chromatography using a Hewlett-Packard HP 6890 series GC equipped with a mass selective detector HP 5973, using the Rest- ek RTX-5 MS capillary column $(60 \mathrm{~m} \times 0.25 \mathrm{~mm} \times$ $0.25 \mu \mathrm{m}$ ), as described in our previous paper (Różalska et al., 2010). The major biodegradation products were 4-Hydroxybenzoic acid; 2-(4-Hydroxyphenyl)acetic acid and 4-Hydroxyphenylpentanoic acid after the samples were derivatized with BSTFA (N,O-bis(trimethylsilyl)trifluoroacetamide). These products were identified using the retention time and mass spectra from MS Calc Pro (ChemSW), Isotope Calculator (NIST) and AMDIS software, and they were confirmed using NIST08 MS library when possible (Słaba et al., 2009; Różalska et al., 2010).

Statistical analysis. The differences among isolates in the mortality rate were determined using a one-way analysis of variance (ANOVA) and the means were compared using a Duncan's multiple range test. The comparisons of LT50 values were made using a probit analysis.

\section{RESULTS}

\section{Molecular identification and phylogenetic analysis}

In total, 37 new sequences were generated for this study and deposited in the GenBank under Accession Numbers presented in Table.2. Amplified parts of the regions (ITS, TEF, MzIGS2, MzIGS3 and MzFG546igs) were placed on a phylogenetic tree (Fig. 1). Tree topology was the same for MP, ML and MB analysis. Most isolates described in this study belong to the $M$. robertsii clade. However, we also observed single isolates from Metarbizium brunneum and M. lepidiotae. M. robertsii, which was described by Bischoff et al. (2009), forms a common clade with $M$. robertsii species described in this paper.

\section{Morphological descriptions and pathogenicity toward G. mellonella larvae}

On PDA, the medium colony pigmentation for various $M$. robertsii isolates is initially white, but when conid- 
Table 2. List of the Gen Bank accession numbers

\begin{tabular}{|c|c|c|c|c|c|c|}
\hline \multirow{2}{*}{ Strain no. } & \multirow{2}{*}{ Name } & \multicolumn{5}{|c|}{ GenBank accession numbers } \\
\hline & & ITS & TEF & MzIGS2 & MzIGS3 & MzFG546igs \\
\hline WA27855 & M. robertsii & JX438659 & JX438645 & KC905143 & KC905149 & KC905137 \\
\hline WA27856 & M. robertsii & JX438658 & JX438644 & KC905144 & KC905150 & KC905138 \\
\hline WA27938 & M. robertsii & JX438653 & JX438646 & KC905145 & KC905151 & KC905139 \\
\hline WA27939 & M. robertsii & JX438654 & JX438647 & - & - & - \\
\hline WA27853 & M. lepidiotae & JX438657 & JX438650 & KC905140 & KC905154 & КС905146 \\
\hline IM 2358 & M. robertsii & JX438655 & JX438648 & KF423435 & KF423437 & KF423433 \\
\hline IM 6511 & M. robertsii & JX438660 & $J X 438651$ & KC905142 & KC905152 & KC905148 \\
\hline WA27848 & M. brunneum & JX438652 & JX438643 & KC905147 & KC905155 & KC905141 \\
\hline
\end{tabular}

ia begin to form, the culture pigmentation becomes pale olivine to dark green (see the colour codes in Table 1 and photos in Supplementary Fig. 1 at www.actabp.pl). Mature colonies are always surrounded by a white margin developed from the mycelium, but it differs in size among isolates. The colony structures are slightly fluffy and low. A visible yellow pigmentation sphere was observed around the colonies for certain isolates. After 14 $\mathrm{d}$ of incubation, the sterile mycelium was sometimes visible in the centre. It should be noted, that variations in colony colour and structure were observed.

The $M$. robertsii conidia are $6-7.5 \times 2.5-3.5 \mu \mathrm{m}$, and the phialides are 2.5-3.0 × 10-16 $\mu \mathrm{m}$ (Table 1). The conidia and phialides sizes were comparable to those measured for $M$. brunneum, while the phialides length for $M$. lepidotiae differed significantly. The investigated isolates from the genus Metarbizium were also pathogenic toward $G$. mellonella larvae; however, the mortality from different isolates and mean lethal times (LT50) varied (Table 3).

\section{Biodegradation of 4- $n$-NP}

Removal of $4-n$-NP (at the concentration $50 \mathrm{mg} \mathrm{L}^{-1}$ ) by the studied fungi is shown in Fig. 2. M. robertsii strains utilize $4-n$-NP very efficiently and after $24 \mathrm{~h}$ of incubation only 6 to $24 \%$ (depending of the strain) of $4-n$-NP remain in the culture extracts. After 48 h of incubation, the detected concentration of the toxic compound in the medium was below $5 \mathrm{mg} \mathrm{L}^{-1}$. It is worth noting that 4- $n$-NP utilization by $M$. robertsii strains differs in dynamics. The strains with the numbers WA27856, WA27938,

Table 3. Average mortality of $G$. mellonella larvae after immersion into conidial suspension of different fungal isolates

\begin{tabular}{|c|c|c|}
\hline \multirow[t]{2}{*}{ Strain } & \multicolumn{2}{|c|}{ Effect on G. mellonella larvae } \\
\hline & Mortality (\%)a & $\mathrm{LT}_{50}$ (days) \\
\hline M. robertsii WA27855 & $97.9 \mathrm{a}$ & 2.9 \\
\hline M. robertsii WA27856 & $100^{a}$ & 2.7 \\
\hline M. robertsii WA27938 & $95.9^{a}$ & 3.2 \\
\hline M. robertsii WA27939 & $100^{a}$ & 2.6 \\
\hline M. lepidiotae WA27853 & $74.4^{\mathrm{ab}}$ & 4.3 \\
\hline M. robertsii IM2358 & $63.0^{\mathrm{b}}$ & 5.1 \\
\hline M. robertsii IM6511 & $98.0^{\mathrm{a}}$ & 4.5 \\
\hline M. brunneum WA27848 & $82.3^{\mathrm{ab}}$ & 3.5 \\
\hline control & $12.5^{c}$ & - \\
\hline
\end{tabular}

aMeans followed by different letters differ significantly (Duncan's test: $P<0.05)$
WA27939 and IM 6511 were efficient at degrading, and removed approximately $90 \%$ of the substrate from the culture medium within the first day of incubation. Another strain $M$. brunneum WA27848 in the first $24 \mathrm{~h}$ of incubation had degradation abilities comparable to $M$. robertsii. After $48 \mathrm{~h}$ of incubation the amount of substrate remaining in the culture extracts was the lowest among all tested Metarbizium strains and amounted only to $0.5 \mathrm{mg} \mathrm{L} \mathrm{L}^{-1}$. Contrary to $M$. brunneum, $M$. lepidiotae WA27853 was the least efficient at $4-n$-NP degradation, and after $48 \mathrm{~h}$ of incubation, $40 \%$ of $4-n-\mathrm{NP}$ was still found in the culture medium.

A GC/MS analysis of BSFTA derivatized fungal extracts showed 4-n-NP degradation products. Because most of the metabolites were produced only in small quantities, three major metabolites for the analysis were selected: 4-hydroxybenzoic acid; 2-(4-hydroxyphenyl)acetic acid and 4-hydroxyphenylpentanoic acid (Table 4). The first metabolite is formed during the final step of $4-n$-NP degradation, immediately before the ring cleavage; 4-hydroxyphenylpentanoic acid is created at the early stages of degradation, while 2-(4-hydroxyphenyl) acetic acid is an intermediate metabolite. The data in Table 4 are consistent with the data in Fig. 2. The relative amount of 4-hydroxyphenylpentanoic acid was the highest in the cultures of $M$. lepidiotae WA27853 cultures, which had the lowest degradation abilities among the Metarbizium strains. The highest level of 4-hydroxybenzoic acid was observed in the cultures with the $M$. robert-

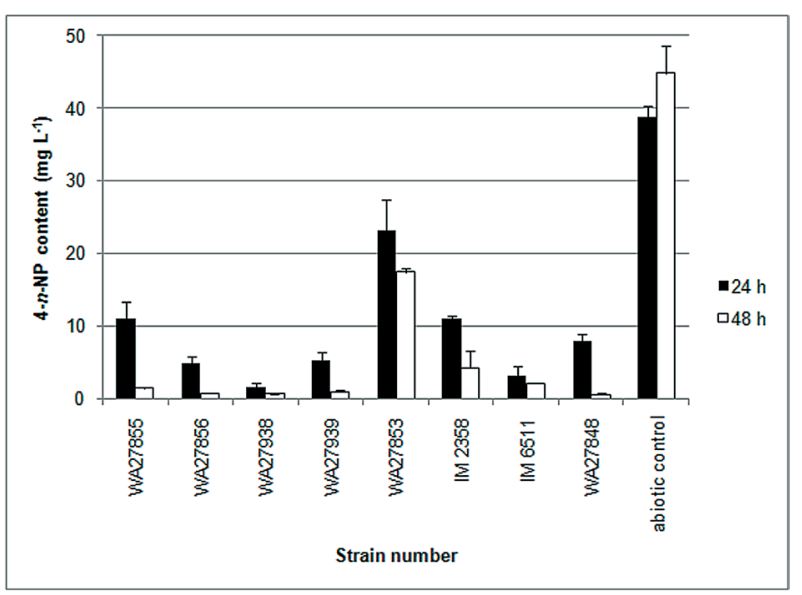

Figure 2. 4-n-NP elimination by the investigated fungal strains. The open bars represent the NP content after $24 \mathrm{~h}$ of incubation, the solid bars are after $48 \mathrm{~h}$. 
Table 4. Relative distribution of the main degradation products after $24 \mathrm{~h}$ of fungal strain incubation with 4- $n$-NP.

\begin{tabular}{|c|c|c|c|}
\hline \multirow{2}{*}{ Strain } & \multicolumn{3}{|c|}{ Relative distribution of the degradation products (\%) } \\
\hline & 4-Hydroxybenzoic acid & 2-(4-Hydroxyphenyl)acetic acid & 4-Hydroxyphenylpentanoic acid \\
\hline M. robertsii WA27855 & $56.26 \pm 3.14$ & $13.39 \pm 0.98$ & $30.33 \pm 2.25$ \\
\hline M. robertsii WA27856 & $66.22 \pm 2.15$ & $19.70 \pm 0.12$ & $14.07 \pm 1.13$ \\
\hline M. robertsii WA27938 & $61.92 \pm 4.91$ & $23.94 \pm 2.11$ & $14.12 \pm 0,98$ \\
\hline M. robertsii WA27939 & $48.93 \pm 3.12$ & $28.84 \pm 1.74$ & $22.21 \pm 1.75$ \\
\hline M. lepidiotae WA27853 & $45.01 \pm 3.74$ & $13.79 \pm 0.08$ & $41.18 \pm 3.65$ \\
\hline M. robertsii IM2358 & $98.28 \pm 0.71$ & $1.34 \pm 0.71$ & $0.37 \pm 0.00$ \\
\hline M. robertsii IM6511 & $84.00 \pm 3.07$ & $6.05 \pm 1.87$ & $9.95 \pm 1.20$ \\
\hline M. brunneum WA27848 & $56.45 \pm 7.16$ & $4.88 \pm 0.35$ & $38.65 \pm 7.52$ \\
\hline
\end{tabular}

sii strains WA27856, WA27938, WA27939 and IM 6511, which confirmed efficient 4- $n$-NP degradation.

\section{DISCUSSION}

ITS sequences are typically used in taxonomic descriptions (Kaszycki et al., 2006), however, they do not separate Metarbizium species well (Bischoff et al., 2006; Bischoff et al., 2009; Kepler \& Rehner, 2013). TEF gene sequences were considered a good diagnostic marker by Bischoff et al. (2009), but discovery of novel clades and intraclade haplotype diversity with 5'-TEF (Rocha et al., 2012) has highlighted the need for new markers with greater resolution. In this work, the "traditional" markers ITS and TEF as well as the newly developed markers MzIGS3, MzIGS5 and MzFg543, as recommended by Kepler and Rehner (2013) were used. Five markers used in this study demonstrate that the $M$. robertsii species described herein are identical with previously described $M$. robertsii (Bischoff et al., 2009; Kepler \& Rehner, 2013).

$M$. robertsii is widespread throughout nature, and it is primarily isolated from soil in different geographic regions (Wyrebek et al., 2011; Rocha et al., 2012). In our work, eight Metarbizium strains are presented and six of them have been identified as $M$. robertsii. The most characteristic feature of the Metarbizium sp. is their pathogenicity toward insects. Thus, during the identification of newly isolated species this feature should be also considered and in our work the pathogenicity of all Metarbizium sp. isolates against $G$. mellonella larvae was also determined.

One of the species isolated herein was identified as $M$. lepidiotae, which until now had the most restricted geographic range among the complex members and has been isolated primarily in Australia, Asia and South America (Bischoff et al., 2009, Schneider et al., 2011). Herein, for the first time it was shown, that the occurrence of this genus is not as limited as it was previously thought.

The natural environment of entomopathogenic fungi is soil, where they permanently contact various toxic substances. High concentrations of pesticides commonly used to control insects and certain fungicides can adversely affect $M$. anisopliae vegetative growth, conidia production and germination (Bruck 2009, Schumacher \& Poehlig 2012). It is worth noting that the literature data on the ability of entomopathogenic strains to degrade hazardous compounds are limited, but the potential application of Metarbizium is promising. Formerly, it was shown that $M$. robertsii IM2358 (previously identified as G. simplex IM 2358) can attack $4-n$-NP, and the xenobiotic degradation path is highly specific and effective (Różalska et al., 2010).

Herein, the abilities of the investigated strains to remove $4-n$-NP from the growth medium were compared. The data show that the strains have an ability to utilize this deleterious compound. Moreover, M. robertsii degrade the compound with similar efficiencies. The literature data on NP degradation by non-lignolytic fungi are limited. Candida aquae-textoris, metabolized $100 \mathrm{mg} \mathrm{L}^{-1}$ of the hazardous xenobiotic during 14 days of incubation (Vallini et al., 1997). The results of this study indicate that $M$. robertsii degrade over $90 \%$ of $4-n$-NP during $48 \mathrm{~h}$ with an initial concentration of $50 \mathrm{mg} \mathrm{L}^{-1}$ for the toxic substrate in the culture medium. Moreover, in our study, the degradation ability within one genus was compared, which had not been investigated previously.

The confirmed degradation capability of Metarbizium strains is connected with the identification of $4-n-\mathrm{NP}$ breakdown derivatives, such as 4-hyroxybenzoic acid. This metabolite was also observed in C. aquae-textoris cultures as one of the major biodegradation products of the xenobiotic (Vallini et al., 1997).

Herein, the slowest degrading strain among the Metarbizium strains studied was $M$. lepidotiae (which also induced the lowest $G$. mellonella mortality), probably because this microorganism grows more slowly than the other Metarbizium strains tested (data not shown). Because the ability to degrade $4-n$-NP by Metarbizium strains is likely a unique feature, further research on $M$. robertsii is necessary to describe the degradation route and compare it with other species in this genus. Such studies are being conducted in our lab and are expected to facilitate identification of useful $M$. robertsii biochemical properties.

\section{CONCLUSIONS}

In the presented paper the Metarbizium isolates ability to effective degradation of 4- $n$-nonyphenol (4-n-NP) was reported. GC-MS analysis revealed the existence of biodegradation products such as 4-hydroxybenzoic acid, 2-(4-hydroxyphenyl)acetic acid and 4-hydroxyphenylpentanoic acid, which confirmed the occurrence of the degradation process. Moreover, a detailed description of 8 new Metarbizium isolates, with the analysis of their pathogenicity against insects was presented. All isolates were identified to a species rank based on five genetic markers. Therefore, we suggest that strains belonging to Metarbizium sp. can be a convenient tool for the studies of 4-n-NP biodegradation. 


\section{Acknowledgements}

This study was supported by the National Centre for Science in Krakow, Poland (Project No. UMO2011/01/B/NZ9/02898) and the Polish Ministry of Science and Higher Education grant NN_303548839.

\section{REFERENCES}

Amóra SS, Bevilaqua CM, Feijó FM, Pereira RH, Alves ND, Freire FA, Kamimura MT, de Oliveira DM, Luna-Alves Lima EA, Rocha M (2010) The effects of the fungus Metarbizium anisopliae var. acridum on different stages of Lutromyia longipalpis (Diptera: Psychodidae). Acta Trop 113: 214-220.

Bernat P, Długoński J (2012) Comparative study of fatty acids composition during cortexolone hydroxylation and tributyltin chloride (TBT) degradation in the filamentous fungus Cunninghamella elegans. Int Biodeterior Biodegradation 74: 1-6.

Bidochka MJ, Kamp AM, Lavender TM, Dekoning J, De Croos JN (2001) Habitat association in two genetic groups of the insectpathogenic fungus Metarbizium anisopliae: uncovering cryptic species? Appl Environ Microbiol 67: 1335-1342.

Bischoff JF, Rehner SA, Humber RA (2006) Metarbizium frigidum sp. nov.: a cryptic species of $M$. anisopliae and a member of the $M$. flavoviride complex. Mycologia 98: 737-745.

Bischoff JF, Rehner SA, Humber RA (2009) A multilocus phylogeny of the Metarbizium anisopliae lineage. Mycologia 101: 512-530.

Brown S, Devin-Clarke D, Doubrava M, O'Connor G (2009) Fate of 4-nonylphenol in a biosolids amended soil. Chemosphere 75: 549-554.

Budziszewska J, Szypuła W, Wilk M, Wrzosek M (2011). Paraconiothyrium babiogorense sp. nov., a new endophyte from fir club moss $H u$ perzia selago (Huperziaceae). Mycotaxon 115: 457-468.

Bruck DJ (2009) Impact of fungicides on Metarbizium anisopliae in the rhizosphere, bulk soil and in vitro. BioControl 54: 597-606.

Cajthaml T, Kresinova Z, Svobodova K, Moder M (2009) Biodegradation of endocrine-disrupting compounds and suppression of estrogenic activity by ligninolytic fungi. Chemosphere 75: 745-750.

Carbone I, Kohn LM (1999) A method for designing primer sets for speciation studies in filamentous ascomycetes. Mycologia 91: 553-555.

Domene X, Ramírez W, Solà L, Alcañiz JM, AndrésP (2009) Soil pollution by nonylphenol and nonylphenol ethoxylates and their effects to plants and invertebrates. I Soils Sediments 9: 555-567.

Edgar RC (2004) MUSCLE: multiple sequence alignment with high accuracy and high throughput. Nucleic Acids Res 32: 1792-1797.

Fernandes ÉK, Bittencourt VR, Roberts DW (2012) Perspectives on the potential of entomopathogenic fungi in biological control of ticks. Exp Parasitol 130: 300-305.

Gouy M, Guindon S, Gascuel O (2010) SeaView version 4: a multiplatform graphical user interface for sequence alignment and phylogenetic tree building. Mol Biol Evol 27: 221-224.

Guindon S, Dufayard JF, Lefort V, Anisimova M, Hordijk W, Gascuel O (2010). New algorithms and methods to estimate maximum-likelihood phylogenies: assessing the performance of PhyML 3.0. Syst Biol 59: 307-321.

Jeon CO, Madsen EL (2012) In situ microbial metabolism of aromatichydrocarbon environmental pollutants. Curr Opin Biotechnol 24: 1-8.

Kaszycki P, Czechowska K, Petryszak P, Miedzobrodzki J, Pawlik B, Kołoczek H. (2006) Methylotrophic extremophilic yeast Trichosporon sp.: a soil-derived isolate with potential applications in environmental biotechnology. Acta Biochim Pol 53: 463-473.

Kepler RM, Rehner SA (2013) Genome-assisted development of nuclear intergenic sequence markers for entomopathogenic fungi of the Metarhizium anisopliae species complex. Mol Ecol Resour 13: 210-217.
Kinney CA, Campbell BR, Thompson R, Furlong ET, Kolpin DW, Burkhardt MR, Zaugg SD, Werner SL, Hay AG (2012) Earthworm bioassays and seedling emergence for monitoring toxicity, aging and bioaccumulation of anthropogenic waste indicator compounds in biosolids-amended soil. Sci Total Environ 433: 507-515.

Langdon KA, Warne MS, Smernik RJ, Shareef A, Kookana RS (2011) Degradation of 4-nonylphenol, 4-t-octylphenol, bisphenol A and triclosan following biosolids addition to soil under laboratory conditions. Chemosphere 84: 1556-1562.

Langdon KA, Warne MS, Smernik RJ, Shareef A, Kookana RS (2012) Field dissipation of 4-nonylphenol, 4-t-octylphenol, triclosan and bisphenol A following land application of biosolids. Chemosphere 86: 1050-1058.

Lisowska K, Szemraj J, Różalska S, Długoński J (2006) The expression of cytochrome P-450 and cytochrome P-450 reductase genes in the simultaneous transformation of corticosteroids and phenanthrene by Cunninghamella elegans. FEMS Microbiol Lett 261: 175-180.

Lomer CJ, Bateman RP, Johnson DL, Langewald J, Thomas M (2001) Biological control of locusts and grasshoppers. Ann Rev Entomol 46: 667-702.

Luque J, Martos S, Phillips AJL (2005) Botryosphaeria viticola sp. nov. on grapevines: a new species with a Dothiorella anamorph. Mycologia 97: 1111-1121.

Milner RJ (1992) Selection and characterization of strains of Metarbizium anisopliae for control of soil insects in Australia. In: Biological Control of Locusts and Grasshoppers. Lomer CJ, Prior C eds, pp 200207. CAB International, Wallingford.

Ojeda G, Patrício J, Navajas H, Comellas L, Alcañiz JM, Ortiz O, Marks E, Natal-da-Luz T, Sousa JP (2013) Effects of nonylphenols on soil microbial activity and water retention. App Soil Ecol 64: 77-83.

Roberts DW, St. Leger RJ (2004) Metarbizium spp., cosmopolitan insect-pathogenic fungi: mycological aspects. Adv App Microbiol 54: $1-70$.

Rocha LF, Inglis PW, Humber RA, Kipnis A, Luz C (2012) Occurrence of Metarbizium spp. in Central Brazilian soils. I Basic Microbiol 52: $1-10$.

Różalska S, Szewczyk R, Długoński J (2010) Biodegradation of 4-nnonylphenol by the non-ligninolytic filamentous fungus Gliocephalotrichum simplex: a proposal of a metabolic pathway. J Haz Mat 180: 323-331.

Schneider S, Rehner SA, Widmer F, Enkerli J (2011) A PCR-based tool for cultivation-independent detection and quantification of Metarbizium clade 1. J Invertebr Pathol 108: 106-114.

Schumacher V, Poehling HM (2012) In vitro effect of pesticides on the germination, vegetative growth, and conidial production of two strains of Metarbizium anisopliae. Fungal Biol 116: 121-132.

Słaba M, Szewczyk R, Bernat P, Długoński J (2009) Simultaneous toxic action of zinc and alachlor resulted in enhancement of zinc uptake by the filamentous fungus Paecilomyces marquandii. Sci Total Environ 407: 4127-4133.

White TJ, Bruns TD, Lee S, Taylor JW (1990) Amplification and direct sequencing of fungal ribosomal RNA genes for phylogenetics. In PCR Protocols: a guide to methods and applications. Innis MA, Gelfand DH, Sninsky JJ, White TJ eds, pp 315-322. Academic Press, New York.

Vallini G, Frassinetti S, Scorzetti G (1997) Candida aquaetextoris sp. nov., a new species of yeast occurring in sludge from a textile industry wastewater treatment plant in Tuscany, Italy. Int J Syst Bacteriol 47: 336-340.

Wyrebek M, Huber C, Sasan RK, Bidochka MJ (2011) Three sympatrically occurring species of Metarbizium show plant rhizosphere specificity. Microbiology 157: 2904-2911.

Venkatesan AK, Halden RU (2013) National inventory of alkylphenol ethoxylate compounds in U.S. sewage sludges and chemical fate in outdoor soil mesocosms. Environ Pollut 174: 189-193. 